\title{
SOBERANIA ALIMENTAR E CAMPESINATO: DISPUTAS TEÓRICAS E TERRITORIAIS
}

\author{
ELIANE TOMIASI PAULINO ${ }^{1}$ \\ Universidade Estadual de Londrina
}

Resumo: O problema da fomeno planeta ganhou centralidade naagenda do desenvolvimentodesde que o pacote químico-mecânico para a agricultura adentrou os países periféricos, pois o número de pessoas com privações extremas aumentou a despeito do crescimento exponencial da produtividade. Depreende-se que tal malogro é resultado da solução prescrita, orientada para a segurança alimentar, cuja via é o mercado e o foco é o abastecimento. Ocorre que o mercado é lócus por excelência do projeto de acumulação que tem a técnica como elo estruturante, daí os limites das inovações convencionais para a agricultura em termos de dinâmicas virtuosas, seja qual for o incremento de produtividade possível em seu seio. Por isso, vislumbra-se como possibilidade a ser construída aquela que transcenda esse modelo alimentar e que seja capaz de culminar em um conceito de sociedade no qual a cooperação e a parcimônia tenham lugar e que, por ora, se expressa melhor no conceito de soberania alimentar. Refletir sobre seus respectivos rebatimentos territoriais à luz das relações de classe, das contradições e das potencialidades que aí pulsam é o propósito desse texto.

Palavras-chave: Soberania alimentar; Segurança alimentar; Técnicas hegemônicas e contra-hegemônicas.

\section{FOOD SOVEREIGNTY AND PEASANTRY: THEORETICAL AND TERRITORIAL DISPUTES}

Abstract: The problem of hunger gained centrality in development projects since the chemimechanical package for agriculture arrived on peripheral countries, where more

\footnotetext{
${ }^{1}$ Professora associada do Departamento de Geociências da Universidade Estadual de Londrina, na área de Geografia Humana. Contato: eliane.tomiasi@uel.br.
} 
people live in extreme deprivation, despite an exponential growth of productivity. Such failure is a result of old strategies for a new solution, because aim is food security, focusing in food provision by the market, where capital accumulation takes place under technical control. So, the limits of conventional agriculture innovations are high, regardless any power increase in the future. However, it is possible improve concept andpratices from food sovereignty, that means not only a transcendent food model but also a society model where cooperation and parsimony may be structured. To reflect about territorial repercussions we are looking for expressions of class relations, contradictions and potentialities.

Keywords: Food sovereignty, food security, hegemonic and counter-hegemonic technics.

\section{Introdução}

Como nexo da ação política a redução da pobreza é um tema em debate tanto quanto a segurança alimentar, o que acabou de ser reafirmado em Istambul por ocasião do East Agre, evento organizado pela FAO e pelo Banco Europeu para a Reconstrução e o Desenvolvimento. Apesar de se tratar de uma estratégia desgastada, cujo insucesso pode ser inferido pela extensão da fome e pela densidade das vulnerabilidades ambientais correlacionáveis ao modelo corporativo incorporado à agricultura, o evento voltou a ratificar o aumento dos investimentos público-privados para compra de terras e modernização técnica como parte do propósito de incremento da produção de alimentos (FAO/EBRD, 2012).

Tanto quanto a política a ciência é parte constitutiva desse problema e também da solução, como provedora de saídas aplicáveis e ao mesmo tempo como meio de identificar a complexa teia de rebatimentos a elas associados. Dado que qualquer intervenção comporta necessariamente as dimensões ambiental e social, esse par dialético se apresenta como realidade. Nesse caso os fatos são contudentes, já que o atual presidente geral da FAO é um intelectual brasileiro, cuja produção tem sido referência para uma parte relevante dos estudiosos que se dedicam aos temas agrários. Portanto, a questão aqui em tela não flui como casualidade, antes é produzida por relações de poder no interior das quais a interpretação, a prescrição e a ação não apenas são indissociáveis das forças em movimento quanto definem o devir imediato e mediato. 
Isso torna imperativo à análise de fenômenos da sociedade capitalista a identificação da primazia da dinâmica de classes com as nuances da geopolítica nela encerradas, porque é daí que provém a concretude do território, esse misto de formas e conteúdos apreensível em diferentes dimensões e escalas.

Mesmo cientes de que a satisfação das necessidades humanas elementares se constitui em impulso primário para todas as estratégias territoriais, perfeitamente inscritas sob a forma de grafias combinadas em sistemas de ordenamento espacial que não deixam dúvida quanto a sua funcionalidade e finalidade, nem tudo é materialidade apreensível, senão por meio do esforço teórico de desvendamento dos seus liames.

A pertinência de uma reflexão crítica sobre o conceito de segurança alimentar que culmine numa maior atenção ao debate sobre soberania alimentar é parte desse corolário, dado que as relações que envolvem a produção e o consumo são complexas a tal ponto que a abordagem orientada pela noção de abastecimento alimentar se mostra insuficiente tanto quanto a prática por ela instaurada. De antemão é preciso pontuar que o conceito de soberania alimentar aqui evocado é produto da práxis, porque forjado nos enfrentamentos de classe em que a dimensão empírica expressa-se na luta por terra/território e a dimensão teórica revela-se no dissenso acerca da sua importância e pertinência, patenteados na conceituação-desconceituação do campesinato.

Não por acaso, a Via Campesina propõe o conceito de soberania a partir de cinco dimensões, a saber: alimentar, energética, genética, hídrica e territorial; as quais tanto são interdependentes quanto supõem uma materialidade objetiva para além do solo, considerando-se a terra como território. Por mais que no seio da ciência esta possa ser alvo de uma naturalização no mínimo equivocada quando tratada como elemento de segunda grandeza no processo de valorização em que objetos e virtualidades parecem ser determinantes, o simples fato de ser insubstituível, irreprodutível, indispensável e escassa faz dela o trunfo primaz.

Para Veltmeyer (2011), no plano em que pulsam dinâmicas econômicas e políticas as quais dão o tom da realidade, o que distingue a teoria da ideologia é que a primeira serve para explicar e a segunda, mobilizar para a ação. E isso é indissociável, exceto no plano analítico, sendo um bom exemplo o conceito de segurança alimentar: instituído como 
resposta à fome no mundo e, simultaneamente, como portador de uma solução, abastecimento, seu teor prescritivo é o da intervenção no mecanismo de oferta de alimentos. Como pressuposto esse é o objeto da ação e não os processos que respondem pela falta deles - entre os quais a interdição em produzí-los -, tampouco a sobreexploração de recursos a uma taxa capaz de comprometer os mecanismos de renovabilidade que são próprios da natureza, já que a ordem intrínseca é a de produzir mais.

Ocorre que a fome é mais produto da mediação do mercado do que propriamente do desabastecimento, estando precisamente em seus mecanismos a origem de uma situação paradoxal em que o desperdício passa a ser a tônica, sendo seu limite a capacidade de compra individual. Subjacente a essa lógica está o desfrute perdulário daquilo que o dinheiro pode proporcionar, ao preço da ruptura com um pacto civilizacional que comporte minimamente o direito à vida no plano imediato. A combinação entre globalização do mercado de alimentos e especulação financeira calcada nesses bens convertidos em ativos é o seu corolário, do mesmo modo que a interdição à comida para os que não puderem remunerar o capital envolvido nesse circuito e, ao mesmo tempo, ao direito de produzíla, para que não forem competitivos segundo tal lógica.

É certo que nem tudo que parece novo o é, uma vez que no contexto da denominada Revolução Verde o aumento exponencial da produtividade na agricultura foi obtido graças a mecanismos artificiais duplamente excludentes: primeiro porque provieram da indústria já organizada sob a égide dos monopólios - o que representou custo extraordinário para o ingresso e permanência no circuito técnico imposto por essa - e segundo porque, como produto da lógica industrial, a eficiência teve como condicionante a escala, tornando cada vez mais difícil o auferimento de renda para os produtores pequenos.

Mesmo que sejam superadas as desvantagens comparativas no âmbito da produção - e isso está suficientemente comprovado pela literatura que se dedica à identificação da lógica cujo fim não é a reprodução do capital -, resta o problema da distribuição do que fora produzido, sobre o que também pesará o preço da desvantagem da produção sem escala. Contudo, nessa esfera as estratégias próprias quase não têm lugar, pois quanto mais articulado for o mercado maiores serão os custos de captação, transporte, logística e comercialização em pequenas quantidades. 
A remuneração do capital como parâmetro na mediação entre produtores e consumidores é o que instaura a sujeição da renda da terra, a qual se revela na dilapidação da receita que caberia aos primeiros, sem que isso signifique vantagem aos segundos - sobre os quais o despojo se faz por meio da sobretaxa nos alimentos à disposição para a compra.

É essa lógica, própria das comunidades e dos mercados locais, que vai progressivamente minando o espaço das trocas virtuosas pelas quais, via de regra, ganham os produtores - que alcançam melhores preços no ato da venda - e também os consumidores - que os tem mais baratos do que no mercado convencional -, exceto em situações de dumping, sistematicamente praticadas pelos grandes varejistas - especialmente nos setores de alta perecibilidade, como os hortifrutigranjeiros. É importante notar que o ônus dessa prática - designada de luva, rapel, bonificação, entre outros - não é absorvido pelo grande setor varejista, mas recai sobre os seus fornecedores diretos; do mesmo modo, recai sobre os camponeses que não têm qualquer vínculo com o grande mercado. Isso porque os primeiros são nada menos que produtores especializados, daí se disporem a entregar gratuitamente a tais cadeias uma parte da sua produção mediante o privilégio de ter acesso a esse poderoso canal de comercialização, que é imprescindível para absorver a sua escala de produção, não raro obtida graças à intensificação do uso do solo que resulta em renúncia da diversificação e, consequentemente, em absoluta dependência do mesmo mercado que abastece. Por outro lado, os camponeses terão o seu mercado potencial inviabilizado, porque é virtualmente impossível competir com preços mais baixos que os custos da produção.

Para os que são expulsos desse circuito, a doutrina neoliberal reserva uma receita: a implementação de políticas públicas que atuem no sentido de que floreçam oportunidades para realizarem outras capacidades, segundo suas próprias competências, e que nesse caso seria vender a força de trabalho, migrar ou começar o "próprio negócio" fora da terra, leia-se, ingressar na informalidade urbana (VELTMEYER, 2011).

Mesmo aos demais com insuficiência de terras e baixa capitalização, a inclusão no mercado segundo os termos mencionados é fonte de permanente vulnerabilização, que pode culminar em exclusão sumária caso haja alguma perturbação de ordem interna ou externa. E o processo de concentração fundiária o comprova, de modo que para muitos a etapa prévia à expropriação é precisamente a especialização produtiva. 
Não por acaso, tais ameaças deixaram de ser intermitentes, sintonizadas com os ciclos da natureza apresentaram como processo estrutural, pelo qual se tem permanências e também mudanças que tendem a reforçar ainda mais as fragilidades da produção camponesa. Compreendê-las, pois, é condição para desfazer os mitos que só têm feito legitimar os consensos hegemônicos, os quais seguem depositando nas mudanças técnicas convencionais as possibilidades de redenção humana, quando elas na melhor das hipóteses poderão oferecer mais do mesmo.

\section{Das intervenções conservadoras à proposta de ressignificação da agricultura}

Dada a profunda relação entre progresso técnico e acumulação de capital, qualquer proposta de análise de uma, de outra ou de ambas requer prudência, até porque a perspectiva da dualidade está tão intrincada no pensamento ocidental que parece ser difícil escapar a essa armadilha. $\mathrm{O}$ fato de essa combinação ter como resultado o que se costuma definir como desenvolvimento nos obriga primeiramente a tomá-lo um processo cuja soma definitivamente não é nula (RAFFESTIN, 1993), já que a sociedade vem sendo beneficiada de inúmeras maneiras, obviamente observando-se um espectro tão amplo de diferenças que mesmo no interior das classes não há aferição possível. Portanto, o esforço de pensar a superação das contradições desse modelo de desenvolvimento não comporta desqualificações simplistas, não raro apresentadas sob a distorção da crítica, como se o propósito dos que a elaboram na prática e teoricamente fosse uma volta ao passado.

Altieri e Toledo (2011, p. 588), após analisar diversos resultados da lavoura de pequena escala na América Latina - onde a tradições camponesa e indígena chegam a ser indivisíveis - quantificaram e qualificaram-na o suficiente para sinalizar suas potencialidades em recuperar recursos naturais com baixa inversão de insumos, produzir comida saudável e empoderar populações. Por essa razão, defendem que as bases para a terceira revolução agrária estariam na agroecologia, um dos pilares do projeto de soberania alimentar. Contrariamente à agricultura industrial, fundada em combustíveis fósseis, produção de escala, biotecnologia e mercado global, essa supõe acesso dos camponeses à terra, sementes, água e mercado local e, complementarmente, criação de suportes institucionais, 
como políticas econômicas, incentivos financeiros e oportunidades de mercado.

Distingue-se também do ponto de vista dos intercâmbios, pois os inputs da agricultura industrial são externos, enquanto que os da agroecologia são internos, em que se busca a recuperação das sementes crioulas, da capacidade de retenção da água pelo solo, do manejo que devolva a sua atividade biológica, combinações essas que favorecem a sustentabilidade e a autosuficiência até porque o saber local passa a ser estruturante, daí o sentido da diversidade e do empoderamento.

Isso a faz distinta inclusive da agricultura orgânica que mesmo tendo como princípio os inputs internos e a compatibilidade ambiental, conserva a dependência para com o sistema de corporações. Portanto, a agricultura agroecológica tem princípios de funcionamento opostos aos das demais, dado que são tomados em sua integralidade e visam a sustentabilidade plena, razão pela qual os autores afirmam que a agroecologia evoca uma soberania alimentar e tecnológica (ALTIERI e TOLEDO, 2011, p. 607).

Paulino, Ferreira e Moreira (2012), ao relatarem os resultados de um projeto de produção de sementes próprias de milho por camponeses no Norte do Paraná, concluiram que as lavouras daí provenientes tanto são economicamente competitivas como investem os agricultores da soberania tecnológica a que se referem Altieri e Toledo (2011), coisa que a opção convencional jamais poderá proporcionar. Faz-se necessário esclarecer que a denominada soberania tecnológica é nada mais do que a associação entre o saber científico e o saber empírico, cujo laboratório é o lugar, os insumos são os recursos que se têm à mão e os cientistas também podem ser eles próprios. Por conhecerem como ninguém os ciclos, os limites e as possibilidades dos cultivos onde mais é necessário na terra da qual têm que tirar o sustento, a simples socialização do conhecimento científico os emancipa. Entrentanto, esse mesmo conhecimento, quando em posse das corporações, aprisiona e é aprisionado, como é o caso das patentes.

Quanto à eficácia do primeiro, dificilmente poderia haver estratégia melhor, uma vez que o alvo das tecnologias de ponta definitivamente exclui os sujeitos que não se constituem em mercado digno de nota, em nome do qual essa arquitetura de progresso técnico está colocada. Mesmo na tradição marxista o progresso técnico convencional soa como alvissareiro, sendo visceral a presunção de sua dissociabilidade possível 
com a lógica do capital, razão pela qual a crítica está focada mais nas formas de controle exercidas sobre as técnicas do que nelas em si.

Entre os estudiosos da agricultura, desde os clássicos prevalece uma leitura na qual o progresso técnico convencional assume a condição redentora, sendo que os parâmetros de eficiência são os mesmos aplicáveis à indústria, daí ser o tamanho da exploração uma condição prévia para que isso aconteça. Embora não seja suficiente para explicar o profundo e duradouro desdém para com as estratégias econômicas empreendidas em pequenas parcelas de solo, e tampouco para com seus agentes por excelência, o fato é que daí também provém o respaldo teórico para a legitimação de um modelo de agricultura socialmente excludente e ambientalmente insustentável.

A descrença daquele que por quase duas décadas fora o editor de um dos mais prestigiados periódicos dedicados aos estudos do campesinato, o Journal of Peasant Studies, pode ser tomada como um indicativo disso:

¿qué tan plausibles son las afirmaciones de los contramovimientos agrarios y sus defensores, en el sentido de que un retorno a los cultivos familiares de pequeña escala de bajos insumos (re-campesinización) pueden alimentar una población mundial varias veces mayor, y tanto más urbana,

que aquella de la época en que los campesinos eran los principales productores de los alimentos mundiales? (BERNSTEIN, 2012, p. 171, grifos do autor).

Por ocasião do lançamento da edição em língua espanhola, da qual foi extraído este fragmento ${ }^{1}$, o autor foi contundente quando indagado sobre a potencialidade da agroecologia no contexto das lutas camponesas capitaneadas pela Via Campesina e que, em síntese, trazem para a cena política o projeto da soberania alimentar aqui debatido. Para ele trata-se de uma proposição romântica e inócua ante o desafio de alimentar a humanidade, tarefa que acredita ser possível mediante o concurso da biotecnologia com especial destaque para os Organismos Geneticamente Modificados (OGMs), desde que, o controle sobre estes saia das mãos das

${ }^{1}$ Conferência proferida na Universidad Autónoma de Zacatecas, México, em 08 de março de 2012. 
empresas e passe para os Estados Nacionais, a exemplo da estratégia ora experimentada na China.

Nesses termos, a proposição do problema e da solução reafirma as estratégias adotadas desde a emergência da segunda revolução agrícola da modernidade, contexto no qual foram incorporados os insumos químicos e a motomecanização, cujo resultado foi um incremento de produtividade a uma escala que não poderia mais justificar e menos ainda explicar a persistência da fome.

De acordo com Mazoyer e Roudart (2010), ainda no período entre guerras, no qual as mudanças técnicas estavam restritas aos países desenvolvidos, as lavouras mecanizadas já alcançavam uma produtividade dez vezes maior que as lavouras manuais, o que nos dá uma ideia do que isso representara para a economia agroexportadora dos países subdesenvolvidos.

Entretanto, como já demonstrara Prado Júnior (1981), nem tudo aquilo que é bom ou ruim para a economia agroexportadora o é em igual medida para os pobres do campo. Enquanto a característica predominante da economia rural foi a baixa monetarização, dado o foco no autoabastecimento, a desproporcionalidade mencionada não foi capaz de inviabilizar a economia de pequena escala, coisa que iria se insinuar ao ritmo da incorporação do padrão técnico gestado no centro do sistema capitalista, pois a possibilidade de concentração do uso do solo oportunizada pela mecanização associada à quimificação é particularmente estimulante para que os proprietários removam os camponeses que, sob os mais variados tipos de acesso condicional, estão em suas terras. Mesmo aos camponeses proprietários as dificuldades de manter-se na atividade são potencializadas quando da plena incorporação da matriz produtiva tecnificada: ela tanto mais aprisiona quanto maior for a dependência no âmbito do consumo produtivo, pois a compra dos insumos em quantidade e qualidade segundo os padrões prescritos passa a ser um imperativo.

Entrementes, paralelamente ao incremento de produtividade os custos da produção têm sido majorados e, ao mesmo tempo, os preços dos produtos agrícolas caíram - exceto no último quinquênio, quando o capital especulativo finalmente aportou com força, o que reafirma a razão direta da escala como fator de rentabilidade na produção convencional. Ao analisar a situação dos pequenos produtores de vinho da região de Mendoza, na Argentina, Ferreyra (2012, p. 15) oferece um parâmetro para 
se compreender esse descompasso: em 2009 o preço bruto recebido pelo litro de vinho a granel correspondia a apenas $21,9 \%$ do equivalente recebido em 1972, com o agravante de que nesse período os custos de produção foram majorados substancialmente. Isso certamente explica a razão pela qual os maiores afetados foram exatamente os menores produtores: entre os estabelecimentos vitivinicultores da região de Mendoza com até 10 hectares, 36,1\% desapareceram somente no período de 1988 a 2002. (FERREYRA, 2012, p. 37). Eis o problema de fundo do ideário da modernização como solução para a eliminação da fome no planeta.

A maioria das pessoas que tem fome no mundo não é [...] de consumidores urbanos compradores de alimento, mas de camponeses produtores e vendedores de produtos agrícolas. $\mathrm{E}$ seu número elevado não é uma simples herança do passado, mas o resultado de um processo, bem atual, de empobrecimento extremo de centenas de milhões de camponeses sem recursos (MAZOYER e ROUDART, 2010, p. 26- 27).

No cenário da denominada agricultura moderna, os limites para a aclamada competitividade dos camponeses estão dados principalmente pela quantidade de terras que dispõem, sendo esta uam discreta variável na análise dos teóricos que insistem em negar textual ou sutilmente a questão agrária contemporânea como se a partilha fundiária fosse bandeira de um passado removido pela modernização técnica no seio da dinâmica do capital.

\section{Técnica e tecnologia: instrumentos do capital ou para o capital?}

Uma questão de fundo a ser considerada é que as técnicas modernas são concebidas e desenvolvidas dentro de um contexto de concentração e é em tais situações que seu nível máximo de eficácia é alcançado. Dentro dessa lógica, a pequena propriedade é uma excrescência, sendo compreensível que os arautos da tecnificação tenham sentenciado a eliminação da pequena exploração e, consequentemente, da viabilidade da reforma agrária. Haveria aqui dois caminhos possíveis: naturalizar a exclusão como produto da técnica ou colocar em questão a técnica 
promotora da exclusão, sendo precisamente nesse ponto que as escolhas teóricas se explicitam.

No tocante à segunda possibilidade, particular contribuição ao entendimento do grau de comprometimento das tecnologias convencionais para com a acumulação de capital - logo, com a exclusão social em escala ampliada - tem sido dada por Bartra (2008), para o qual a dimensão técnica dependente do modelo de produção, distribuição e consumo hegemônicos não se configura apenas como instrumento de acumulação, mas como expressão do ordenamento extorsivo típico do capital - social e ambientalmente falando.

Ao estabelecer uma profunda vinculação entre o aparato tecnológico e a racionalidade capitalista, Bartra o faz a partir de uma inversão do olhar que o aproxima mais dos ludditas do que dos marxistas, pois refuta veementemente a tese de que o problema está mais na propriedade dos meios de produção do que propriamente na impossibilidade de acioná-los segundo uma racionalidade social e ecológica. Inspirado nas próprias proposições de Marx, procura revelar como as astúcias do capital se traduzem em ofuscamentos a ponto de persuadir-nos de que a tecnologia pode ser apreendida fora da lógica que a empreende. Por isso assevera que, mesmo Marx, ao propugnar em seus manuscritos a tese de que as máquinas podem ser empregadas de forma mais adequada do que o fazem os capitalistas, acaba por explicitar um entendimento de que elas podem ser boas ou más, dependendo de quem e para que as utiliza. Por isso, propõe a releitura de sua obra com os mesmos referenciais da dialética aí contidos, pois do contrário incorrer-se-á no risco de legitimação da ordem imanente ao paradigma contemporâneo.

[...] los ludditas, que hacen doscientos años le echaban la culpa a las máquinas, siguen teniendo razón en lo fundamental. Para ellos, como para mi, la cuestión debe ser planteada precisamente a la inversa: el problema no radica tanto en la propriedad de medios de producción como en la naturaleza de estos medios, que está determinada porque su propósito es la valorización y esto los lleva a la especialización e intensificación productiva, es decir, a la erosión de la diversidad humana y natural. (BARTRA, 2008, p. 87) 
Há convergências entre tal assertiva e alguns apontamentos de Santos (2002), para quem o maior aliado do capital é o consenso em torno da via demarcada pelo mercado e regida pela racionalidade técnica primaz. Consequentemente, a tarefa da burguesia de aprofundar seu projeto societário tanto será mais simples quanto for a renúncia da sociedade em buscar outras possibilidades.

Trata-se de indagar: as evidências do mundo sensível que sinalizam para a improbabilidade de um outro devir que não seja o fundado na divisão do trabalho e na megaconcentração nos termos hoje conhecidos são suficientemente fortes para reafirmar o desalento imobilizante? Há sinais de que as benesses do progresso técnico até então desfrutadas às expensas de muitos que aí estão e dos que virão poderão ser abrangentes e longevas?

No que tange ao ordenamento territorial, Calabi e Indovina (1973) afirmam que sob a égide da acumulação as dinâmicas espaciais estão inapelavelmente aprisionadas por mecanismos que visam o fechamento do ciclo de valorização do capital, no qual a mercadoria é condição precípua, daí a funcionalidade das cidades como pontos vitais de adensamento. Para isso a densidade técnica é determinante, razão pela qual Bartra é categórico, ao afirmar que por ser a lógica da acumulação a força motriz do paradigma técnico não há como vislumbrar uma neutralidade possível na presunção de que está posto um projeto civilizador, na exata acepção do termo.

Romper com a ideia de que as técnicas hegemônicas ora apresentadas como promissoras poderiam ser benéficas caso o controle estivesse em poder dos trabalhadores é o que propõe Bartra, que convida ao reposicionamento em relação à utopia que coloca em movimento a construção do devir. Do mesmo modo que o horizonte está para a resignação paralisante ou para a aposta no progresso humano postergável igualmente parceira do imobilismo -, as contradições daí advindas são suficientemente fortes para mobilizar as forças criadoras do processo de transformação que só virá se assim for construído. E vislumbrá-lo fora dos marcos das técnicas hegemônicas aprisionadas no circuito das mercadorias é uma condição prévia e fundante.

Se o padrão agrícola fundado na mecanização e na quimificação parecera promissor há um século, quando as teorias agrárias nascentes o tomaram enquanto marco entre o progresso e o atraso, a história não só encarregou-se de revelar a dose de otimismo nelas contido conforme 188 
Shanin (1980), quanto trouxe para a cena justamente os sujeitos rechaçados cujas práticas novamente se insinuam como um repositório de estratégias viáveis e transcendentes (DESMARAIS, 2007), em contraposição ao cenário de vulnerabilidades implicadas na fome e na crise ambiental contemporânea.

É nesses termos que o debate sobre a soberania alimentar se coloca. Porque se ele é indissociável de um conceito de produção de pequena escala no qual a tônica é a autogestão e a diversidade criativa e criadora, é também pensado na perspectiva dos circuitos curtos de distribuição e consumo, cujo diferencial está na parcimônia energética e no pressuposto das trocas virtuosas, em que há lugar para muitos. Nisto consiste sua essência implosiva do ponto de vista da acumulação de capital, em que a outra face da lógica excludente é a dissipação negligente que se viabiliza justamente pela existência de consumidores alhures. São os limites imanentes a tal lógica que imprimem o ritmo ascendente da orgia consumista, a qual não suporta adiamentos exatamente em função do seu caráter autofágico, como demonstrado por Harvey (1996).

Seu rebatimento espacial é inconfundível porque é nas regiões provedoras de matérias-primas e força de trabalho barata que as tragédias humanitárias são potencializadas. Não por acaso, durante décadas o conceito de segurança alimentar foi invocado no contexto do ideário do desenvolvimento, que a teve como alvo. Assim, pavimentaram-se os caminhos para o livre arbítrio do mercado embalando as estratégias que deram o tom da diplomacia do capital.

Para Parpart e Veltmeyer (2011, p. 21), o próprio conceito de desenvolvimento foi instituído e empregado como parte de uma estratégia geopolítica cujo fim era a contenção da ameaça socialista no contexto da Guerra Fria. Por isso, buscou-se a adesão dos países recém-saídos da dominação colonial ao projeto de democracia típico do capitalismo da Europa Ocidental e América do Norte, o mesmo valendo para os chamados países subdesenvolvidos na ocasião, muitos dos quais em efervescência ameaçadora à ordem burguesa, sendo a América Latina o melhor exemplo.

Se o desenvolvimento aparecia como a possibilidade de encontro com o projeto civilizatório prometido desde a época das luzes, em termos institucionais o parâmetro manteve-se fiel à lógica de acumulação que já havia culminado num mundo em destroços, cuja reconstrução pontual fora utilizada para sinalizar uma suposta capacidade de generalização do Estado 
de bem-estar social. A receita foi a do crescimento econômico, razão pela qual até hoje persiste a utilização de ambos, não raro, como sinônimos. Segundo Parpart e Veltmeyer (2011, p. 24) os termos desse conceito de desenvolvimento se cristalizaram na política de industrialização, tomada como único caminho para atingí-lo. O aumento da taxa de poupança interna a ser direcionada prioritariamente para o investimento na indústria com ações estruturais de fortalecimento dos setores essenciais pelas mãos do Estado como forma de compensar a baixa capacidade de investimento privado, a proteção das empresas contra a competição externa e a expansão do mercado interno foram algumas das estratégias adotadas pelos países periféricos; sem que a fome - expressão mais aguda das contradições gestadas em seu bojo - desse sinais de recuo, muito pelo contrário.

Se de um lado o esvaziamento das promessas impõe a busca por alternativas, por outro requer um olhar mais atento para a dinâmica das disputas entranhadas na modernidade, na qual duas racionalidades se confrontam: a capitalista e a camponesa.

\section{Camponeses no contexto das abordagens e das lutas de classe}

Mais do que uma disputa em torno da riqueza oriunda do trabalho, cada vez mais vulnerável, as lutas camponesas expressam um desencontro mais amplo com a lógica do capital, na qual está em questão também o modo de produzir a riqueza. Enquanto a luta dos trabalhadores contra o capital tem como limite a necessidade de conservá-lo para preservar a si próprios, a dos camponeses revela o esforço contra a assimilação que significaria a sua destruição enquanto tal.

De acordo com Portes e Hofman (2003, p. 40) o decréscimo dos salários e a piora das condições de vida do trabalhador no contexto das reformas neoliberais não resultou em fortalecimento das lutas. Muito mais que a força repressiva dos exércitos, para isso foi decisivo o fechamento de fábricas e demais possibilidades de emprego formal. Em suma, o desemprego tornou-se o fator domesticador dos trabalhadores, que perderam renda, dignidade e participação política, havendo inclusive recuo em termos de representação autêntica na composição dos respectivos parlamentos. Daí os autores afirmarem que o aspecto mais exitoso do neoliberalismo não foi o econômico, mas o político, pelo enfraquecimento da capacidade de enfrentamento laboral. 
Por sua vez, foi no contexto do neoliberalismo que as lutas camponesas e indígenas ressurgiram com intensidade singular, porque enquanto para os trabalhadores o avanço das determinações do capital se materializam em precarização do trabalho, para os camponeses e indígenas ela supõe expropriação. Diria Wolf (1984) ser esse o combustível de todas as revoluções do século XX.

O controle da terra, dos instrumentos de trabalho, do trabalho e do saber que os aciona para a obtenção de bens reais e comida, diga-se de passagem, é uma condição de classe qualitativamente única. Independentemente de como ou quanto disso vai para o mercado e, por outro lado, de quanto vem do mercado para que isso aconteça, o fato é que no limite, se interditadas todas as trocas, eles podem não perecer. Disso resulta que a potencialidade de se fazer por si próprios é uma condição estrutural enquanto a dependência é uma condição conjuntural, estando precisamente aí a potencialidade da superação da ordem do capital. Por sua vez, o fazer-se enquanto trabalhador expropriado supõe a dependência do capital como condição estrutural, porque é daí que provém a licença para tomar parte do processo produtivo. Mesmo os informais e autônomos não têm como fazer-se por si próprios, porque o mercado é um elo do qual definitivamente não podem prescindir.

A contundência da expropriação advém disso. De acordo com Otero (2004, p. 252), a tese proletarianista que orientou suas pesquisas sobre o campo mexicano foi refutada pelas evidências da realidade precisamente quando passou a dedicar-se aos estudos urbanos. Foi aí que concluiu que mesmo nas áreas mais proletarizadas as demandas dos trabalhadores eram eminentemente camponesas, capitaneadas no sonho da terra própria e autoabastecimento alimentar.

Por sua vez, Almeida (2006) encontrou no conceito de habitus de classe de Pierre Bordieu os elementos que lhe permitiram compreender a trajetória inversa dos filhos de camponeses que herdaram dos pais somente o sonho pela terra, acalentado nas periferias urbanas, onde se construiu o habitus da luta - impulso que os fez tomar o caminho cidade-campo, trilhado primeiro em acampamentos e depois em assentamentos da reforma agrária.

Portanto, posicionar-se ante às teses que os apresenta como funcionais, úteis ou dispensáveis requer uma análise pautada na perspectiva dialética, porque do contrário admitir-se-á que é o capital quem 
concede a licença para os camponeses existirem. As revoluções, guerras e conflitos localizados, em plena efervescência, são uma evidência de que se eles aí estão isso se deve às suas lutas.

Sob a égide do capital, camponeses e populações tradicionais representam duplo obstáculo: o controle de uma porção de terra e de recursos que para eles é meio de vida representa a subtração de uma fração do que poderia ser meio de acumulação e os recentes posicionamentos mencionados da FAO e do EBRD indicam isso. Por outro lado, a própria indisponibilidade dessa força vital, segundo a conveniência do capital, somente é desdenhada onde e quando a tarefa da expropriação foi consumada e pode perpetuar-se, daí o papel inalienável do progresso técnico. Quando não for prevalecerão as formas violentas e desumanizadoras de coerção ao trabalho.

Esse processo, que possui dimensão planetária, exprime uma das faces da geopolítica que requer um olhar sobre o conteúdo de classes inerente ao Estado Nacional moderno, sob pena de se cair em abstrações caras à concepção clássica. Segundo Petras e Veltmeyer (2003, p. 33) os Estados neoliberais são essencialmente imperialistas e neomercantilistas e sua ação está no centro da atividade econômica. Segundo os autores ela se reveste de uma estratégia em duas direções: internamente promove-se a proteção dos capitalistas domésticos que não são competitivos e externamente busca-se uma abertura forçada dos mercados periféricos. Como a agricultura é um dos setores mais subsidiados, os governos dos países centrais adotam medidas para proteger os produtores ineficientes, ao mesmo tempo em que criam barreiras sanitárias e tributárias para impedir a competição externa. Não se equivocara Chesnais (2012) ao afirmar que o eixo da política nacional não é a proteção do Estado de seus inimigos externos, mas sim da sua própria população - assertiva que tem como base a análise de inúmeros documentos confidenciais tornados públicos. Essa é a evidência de que a luta de classes precede à geopolítica porque ela se dá no plano interno aos países. Reafirma-se, assim, o postulado de que o Estado Nacional é invenção e condição do funcionamento da sociedade burguesa.

Cabe lembrar, no entanto, que o mecanismo das trocas desiguais não é suficiente para bloquear a acumulação da burguesia agrária e dos proprietários rentistas nos países periféricos, já que seus Estados igualmente imputarão tal ônus para outros. Exemplo disso é o subsídio 
indireto conferido ao denominado agronegócio no Brasil, em que essa proteção emana de um pacto interno de classes. Nesse pacto prevalece a estratégia de evocar as receitas liberais apenas para aos que estão de fora. A paralisação das negociações no interior da denominada Rodada de Doha, que deveria ser o último ato da completa liberalização dos mercados globais, pode ser citada como exemplo.

Essa, que fora a nona reunião desde a criação do Acordo Geral de Tarifas e Comércio (GATT) e a primeira relativa a negociações multilaterais no âmbito da Organização Mundial do Comércio (OMC), emperrou exatamente pela natureza das concessões exigidas aos países ricos, coisa que não ocorreu nas rodadas anteriores quando os termos das trocas dos bens industriais foram impostos sem empecilhos dignos de nota. Entrementes, o que fez o Brasil anunciar o retorno à mesa de negociações, abandonada após o impasse, é a expectativa pelo abandono das políticas protecionistas que redundam em diminuição da lucratividade do agronegócio brasileiro.

O caráter de classe dessa investida é notório porque o que se advoga é a ampliação das margens de negociação para os produtores que, por diversas razões - incluso subsídios disfarçados - já são competitivos no plano externo: há um conjunto de medidas estruturais no plano interno que tem exatamente o mesmo caráter protecionista que os faz vociferar. Entre eles descata-se a isenção do Imposto sobre Circulação de Mercadorias e Serviços (ICMS) aos produtos agrícolas exportados, a renúncia do Estado aos créditos correspondentes às dívidas agrícolas não saldadas sob o manto das securitizações, bem como a expansão contínua dos créditos agrícolas subsidados dentro de uma lógica hierárquica de justiça social às avessas.

Prova disso é que o mesmo Estado que cria uma divisão arbitrária para justificar um aporte de recursos públicos desproporcionais aos que denomina agricultores familiares, os reconhece como os responsáveis por $38 \%$ da produção em valor da agricultura brasileira (IBGE, 2009). No plano safra 2012/2013 lhes foi designado 13,5\% dos recursos, cabendo aos assim denominados agricultores comerciais $86,5 \%$ da fatia orçamentária para o fomento agrícola. A mencionada divisão também foi objeto das críticas de Navarro (2010, p. 206), assim expressa:

O principal argumento [...] reside na necessidade de ir além da noção simplificadora de agricultura familiar, e não apenas por razões teóricas. A respeito destas, insiste-se que o estatuto 
de tal noção é meramente descritivo, não se constituindo enquanto categoria conceitual e, desta forma, não se sustenta em nenhuma tradição científica. Mas [...] existem também razões práticas e políticas, e estas estão domiciliadas na crescente percepção de ineficácia na implementação da ação governamental que tem foco naquele grande grupo de produtores.

Ocorre que tal assertiva não exprime uma crítica à assimetria nas políticas públicas em decorrência da arbitrariedade conceitual. Ao contrário disso, coloca em suspeição exatamente a legitimidade de uma política diferenciada para os designados agricultores familiares, sobre isso, vejamos:

[...] é um óbvio nonsense manter duas políticas de financiamento à produção e dois ministérios criando políticas que pretendem disputar uma clientela (os produtores) que, na realidade do mundo rural, não competem entre si, pois seus competidores reais (ou as ameaças que sofrem) estão em outros pontos da cadeia produtiva. Sem meias palavras: este é um contexto institucional que impede a formulação de uma política real de desenvolvimento rural para o Brasil, ação governamental que nunca existiu na história brasileira e, persistindo tais equívocos institucionais, jamais existirá (NAVARRO, 2010, p. 196, grifo do autor).

Tais proposições mostram quão árdua é a tarefa de construir um projeto societário pautado na equanimidade porque a homogeneização pretendida é parte da ofensiva dos ruralistas contra algumas conquistas do campesinato brasileiro. As lutas que já custaram a vida de milhares deles e seguem fazendo vítimas - afora as perdas não contabilizáveis em desterro, perseguições e privações perenes -, conforme se pode inferir em consultas desde publicações acadêmicas até páginas policiais, tornam a afirmação de que os produtores brasileiros não competem entre si no mínimo uma ofensa à memória dos que tombaram e uma provocação aos demais.

Não é difícil entender, portanto, o caráter político da desconceituação. Porque sob o manto da assepsia ideológica a premissa da diluição das classes favorece o ocultamento das hegemonias cujo resultado concreto é o provimento material que flui de políticas públicas, o instrumento de transferência da riqueza social em proporções desiguais. À 
diferença de que na tradição positivista estratégias da classe dominante não são tomadas como ideologia, mas como racionalidade virtuosa.

Em síntese, a ação do Estado a favor dos mais pobres do campo poderá ser fortemente ampliada e aprimorada a partir de fundamentos mais racionais e correspondentes às realidades agrárias do Brasil. Quem sabe se poderá divisar então uma política real de desenvolvimento rural que finalmente emancipe o mundo rural e seus cidadãos, aportando-os à modernidade capitalista enquanto um padrão civilizatório, e não apenas enquanto um setor de produção econômica (NAVARRO, 2010, p. 206, grifo do autor).

Ocorre que a modernidade capitalista está circunscrita no receituário neoliberal, no qual a crítica às políticas sociais encobre o silêncio sobre as estratégias de locupletação que não admitem partilha. Por isso, a ação eficiente do Estado é aquela que remove eventuais obstáculos para que os sujeitos investidos de condições diferenciais concorram como se estivessem em posição de igualdade. Se essa é a receita para que o mercado cumpra suas virtuais potencialidades num ciclo de controle desigual no âmbito da produção, distribuição e consumo, é também o limite para o que se vende como devir auspicioso, a nova receita de uma ciência que advoga soluções para problemas que são menos técnicos do que políticos.

É o conteúdo das hegemonias, incluindo as de ordem teóricoconceituais, que poderá explicar a falta de sincronismo entre a realidade e o tratamento que lhe é dado, expresso em uma dupla combinação entre a exposição contundente de um vir a ser que nunca chega e a omissão velada ante o resultado da luta de classes; passível de ser medido na assimetria das políticas públicas em prejuízo dos mais vulneráveis, na degradação dos termos de troca que a concentração da produção impulsiona, na desregulação dos mercados e na especulação - evidência de que a modernidade capitalista aí está menos para solucioná-las do que para aprofundá-las.

A emancipação condicionada à modernização técnica é ardilosa porque a técnica não é neutra, antes, está a serviço da acumulação, que necessariamente se fará às expensas de recursos naturais e de trabalho, as duas fontes de riqueza que, segundo Marx (1974), lhes são estruturais. Portanto, fome e degradação ambiental são as expressões extremas dessa 
lógica, daí que a cada ciclo de expansão econômica as vulnerabilidades sociais se insinuam com mais força - momentos em que as mediações parecem ser decisivas para conter eventuais colapsos que poderiam atentar contra a ordem estabelecida. Mediações que podem até atuar positivamente, pontual e conjunturalmente falando, sem que isso interfira no sentido de afastar os riscos iminentes que são de ordem estrutural.

Uma breve revisita ao ocorrido no último século o confirma, dado que o saldo da expansão capitalista global foram duas guerras mundiais entremeadas por profunda depressão econômica no seio das quais emergeria a nova ordem - antropofágica -, diga-se de passagem, porque a força dos atores da nova hegemonia global está na capacidade de submissão dos vencidos e da apropriação da cota de recursos e energia vital correspondente. Como apropriadamente identificou Chesnais (2012), o que ora se insunua como crise profunda e duradoura nada mais é do que os sinais de que a burguesia está se movendo cada vez mais no sentido de preservar a dominação de classe em toda sua crueza; a materialidade técnica forjada sob seu controle nunca fora tão favorável quanto agora.

Daí a acertada associação feita por Bartra (2008) ao homem de ferro, síntese do modelo de acumulação forjado entre o final do século XVIII e o início do século XIX que culminaria no que denomina factum tecnológico: a partir da segunda metade do século XX ele iria aparecer sob a forma de bomba, de energia nuclear, de Revolução Verde, de transgênicos, entre outros - que acabariam por criar as condições para a privatização e controle em dimensões antes insuspeitas. É de se supor que essa marcha não teria sido vitoriosa não fossem os instrumentos da ciência, não somente aqueles de natureza aplicada - restrita ao campo da produção, distribuição e controle da riqueza -, mas também os de caráter legitimador. Nesse sentido é imperioso reafirmar que a aposta no pleno desenvolvimento das forças produtivas capitalistas como condição para a redenção da humanidade não se restringe aos setores conservadores, alinhados com os interesses hegemônicos, antes, o melhor tratamento teórico deste princípio está na produção de cunho marxista ortodoxo, na qual, não raro, a técnica foi elevada à condição de protagonista do que parecia ser o destino manifesto e inexorável da humanidade: uma sociedade de iguais.

Coerente com uma leitura linear da realidade, a concepção de que o capitalismo seria a antessala do comunismo opôs-se à pedra angular da interpretação marxiana, que coloca na consciência crítica o caminho para a 
liberdade - essa que é o cerne da utopia que confere sentido e mantém atual a obra de Marx, malgrado a necessidade de se atentar aos contextos e as releituras que ela impõe.

É por isso que Bartra (2008) considera imperioso o desapego das amarras da ortodoxia, condição para desarmar aquilo que para ele seria uma armadilha: o determinismo econômico embalado pelo ideário do progresso técnico, o qual seria prenhe de uma leitura legitimadora da conversão tanto dos seres humanos quanto da natureza em mercadoria. E a dinâmica das mudanças técnicas ante o paradigma da biotecnologia melhor o expressa: a racionalidade que lhe é inerente é incompatível com a perpetuação da vida segundo seus próprios ciclos porque fundada em princípios que se são imprescindíveis à reprodução do capital, violam a natureza em todas as suas expressões.

Bartra vai além ao correlacionar a crença na potência transformadora do progresso técnico aos recuos políticos da contemporaneidade, pois atribui a isso a falência do socialismo de Estado e com ele a perda de parâmetros para o projeto emancipatório há muito acalentado pela humanidade. Não que Bartra faça a crítica com base na lógica formal, a qual nos levaria a crer que o fim dessa experiência é uma evidência de que as forças livres do mercado são o caminho natural da sociedade. No entanto, a apresenta a partir da lógica dialética porque vislumbra na capacidade de mobilização que culmina em diferentes formas de enfrentamento da ordem capitalista a evidência de que o desejo de emancipação não morreu. Em sua latência estão dadas as possibilidades de transformação.

É precisamente no elemento mais desdenhado pelo marxismo ortodoxo que seguem vivas as potencialidades de construção de outro projeto civilizatório: a lógica de produção econômica e reprodução social dos camponeses, depositária respectivamente da parcimônia ambiental e da cooperação, que são estruturantes do conceito de soberania alimentar. Por isso sentenciou Shanin (2008) que temos mais a aprender do que a ensinar a eles. 


\section{Considerações finais}

Reconhecer o patamar de interdependência econômica no mundo em que seguramente se pode falar de um mercado global - é condição para igualmente se indagar acerca de seus desdobramentos territoriais, que certamente refletem essa escala. Se as condições concretas sob as quais erigiu-se a indústria em que a natureza das mercadorias jamais fora um empecilho para a circulação, daí a amplitude global das trocas ainda nos seus albores no sentido da origem e do destino de alguns produtos, isso não tinha como comprometer severamente a outra ponta da cadeia produtiva - a agricultura - da qual provém o fornecimento regular de matéria prima.

Por sua vez, enquanto prevaleceu o princípio da autosuficiência como estratégia defensiva naquilo que é condição inalienável à existência os alimentos - o risco de desabastecimento esteve condicionado às situações de guerra e às vicissitudes da natureza, recorrentes o suficiente para provocar inumeráveis crises de fome.

$\mathrm{O}$ incremento da produtividade, das condições de armazenamento, conservação e distribuição no contexto da primeira e da segunda revolução agrícolas modernas reduziria significativamente esse risco, sendo, pois, de se esperar que as crises de fome recuassem ao mesmo ritmo. Entrementes, isso não ocorreu. Em números absolutos, a quantidade de pessoas que sofrem de fome crônica - o que significa não terem acesso à quantidade mínima de alimentos diariamente - está estimado em um bilhão, mas, se a esses forem somados os que têm deficiências nutricionais em vista da interdição à qualidade alimentar, chega-se a dois bilhões de pessoas no planeta (MAZOYER e ROUDART, 2010).

Paradoxalmente a maior parte das pessoas privadas de alimentação mínima vive no campo, o que significa dizer que não são os compradores, mas sim os pequenos vendedores de alimentos as maiores vítimas do progresso técnico na agricultura, o que sinaliza para o engodo das políticas convencionais de eliminação da fome, as quais foram gestadas no contexto da segurança alimentar cujo objetivo expresso é o do abastecimento dos mercados, como se aí estivesse a origem do problema.

[...] aproximadamente três quartos dos indivíduos subnutridos do mundo pertencem ao mundo rural. Homens do campo pobres, dentre os quais encontramos, majoritariamente, camponeses particularmente mal 
equipados, instalados em regiões desfavoráveis e em situação difícil, assim como trabalhadores agrícolas, artesãos e comerciantes que vivem em contato com eles e que são tão pobres quanto eles. Quanto aos outros subnutridos, muitos são ex-camponeses recentemente forçados pela miséria a irem para os campos de refugiados ou periferias urbanas subequipadas e subindustrializadas, nas quais eles ainda não puderam encontrar meios de subsistência satisfatórios (MAZOYER e ROUDART, 2010, p. 26).

Otero (2004) o reafirma, ao apontar que a pobreza urbana não poderá ser compreendida em separado da pobreza rural, dado que lança nas cidades exércitos de pessoas que não têm aí oportunidade de sobrevivência. Para ele tanto os problemas urbanos quanto os problemas agrários não são senão aspectos do mesmo processo de desenvolvimento capitalista.

Acrescente-se que tais vulnerabilidades tanto são de caráter estrutural quanto revelam outro estágio do processo de acumulação, porque a instituição de um mercado global para os alimentos permite o descolamento para com a escala do local seja no tocante à renda circulante nas mãos dos trabalhadores que devem comprá-los, seja na da oferta dos camponeses que os produzem em pequena quantidade.

No contexto em que o controle da produção, distribuição e consumo é exógeno, há outro agravante a depor contra a produção camponesa de caráter diversificado e profundamente enraizada com a cultura alimentar, o que fizera, aliás, Porto Gonçalves (2006) identificar precisamente a distinção entre agricultura e agronegócio. $\mathrm{Na}$ atualidade não se poderá desdenhar o impacto da fabricação de gostos associados a não comidas, no sentido cultural e nutricional do termo, cujo impacto pode ser medido na saúde dos consumidores, mas também nas possibilidades de reprodução da categoria agricultores, como o são os camponeses no sentido estrito.

Sobre essa estratégia já se debruçara Ploeg (2008), ao mostrar que a taxa de lucro da indústria alimentar na atualidade, que não possui paralelos nos demais setores da economia, advém da sua capacidade de produzir comidas sem agregar os ingredientes correspondentes, quantitativa e qualitativamente falando. Portanto, afora aspectos de saúde pública, a possibilidade de forjar alimentos a partir da apropriação do conceito de nobreza e qualidade próprios aos de verdade tem desdobramentos territoriais. E é importante identificá-los porque a artificialização dos 
gostos atenta contra a sustentabilidade dos produtores e dos mercados locais.

Um fato despretensiosamente noticiado há tempos em um telejornal vespertino o ilustra: como parte da proposta pedagógica com ênfase na aprendizagem da geografia local em uma região viticultora do Rio Grande do Sul, empreendeu-se um projeto para que escolares conhecessem e compreendessem a importância econômica dessa atividade e o diferencial em termos de qualidade do suco de uva típico. No entanto, no ato da degustação, em que fora servido a bebida natural e também uma artificial sem a respectiva identificação da origem, apenas duas crianças, em um grupo provavelmente suficiente para lotar um ônibus, demonstrou a preferência pelo suco natural.

Por mais que esse fato não se preste a comprovação de teses dentro dos cânones metodológicos reconhecidos pela ciência, é suficiente para sinalizar a conquista de posições das corporações do que se pode denominar "junk food" frente aos produtores de comida, fato tanto mais ameaçador quanto forem as condições de renda da população, já que o custo dos fabricados necessariamente é baixo, sendo o preço uma variável tanto mais flexível quanto for a elasticidade da demanda.

Portanto, as respostas a serem dadas no tocante ao problema dos alimentos é muito mais complexa do que querem os entusiastas do progresso, que seguem apostando para a solução com a administração do veneno em maior quantidade, devidamente reembalado pelas novidades técnicas da biotectologia - cujo conteúdo é um estágio ainda mais refinado de monopolizações, em que as exclusões serão o resultado necessário.

Precisamente nisto difere o projeto subjacente ao conceito de soberania alimentar. Como demonstrado por Rosset (2006), não se trata tão somente de assegurar alimento às pessoas, mas também acesso aos mercados pelas pessoas que produzem alimentos, por isso adverte que soberania é um conceito que vai além do direito à alimentação. De acordo com o autor, o conceito de soberania supera o conceito de segurança alimentar na medida em que para alcançar a soberania, a inserção no mercado pelos agricultores locais é determinante.

A ideia de soberania alimentar foi inicialmente introduzida pela Via Campesina, segundo a qual são as comunidades locais que devem exercer total controle sobre os recursos e métodos de abastecimento de comida, 
contrariamente à ideia de eficiência na produção e distribuição própria do sistema global da cadeia alimentar.

Enquanto no modelo dominante o foco está na necessidade de garantir alimentos em quantidade suficiente para todos, independentemente de como e onde ele é produzido e, da mesma forma, sem contemplar princípios no tocante ao direito para produzir ou consumí-los, o conceito de soberania alimentar se apresenta como contraponto porque é na negação de tais princípios que se poderá encontrar a explicação para a fome e desnutrição de milhões de pessoas no mundo.

Nesse sentido, Desmarais (2007) incita o reposicionamento ante o conceito de campesinato, por entender que, longe de referir-se a um extinto ou idealizado modo de vida, consiste em vibrante setor da sociedade por lhe ser inerente o princípio da unidade na diversidade, o que favorece uma articulação que também pode ser global. Entretanto, diferente da lógica do capital, é portadora de um modo distinto de viver em comunidade porque baseado num critério universal de justiça social e igualdade.

Por isso, continua mais atual do que nunca a compreensão que privilegia a reforma agrária e o apoio público à produção camponesa, sendo o caso brasileiro contundente, pois ao tomar-se como parâmetro o módulo fiscal, unidade de área mínima para a sobrevivência de uma família, verifica-se que $65 \%$ dos agricultores detêm uma área inferior ao mínimo estabelecido como economicamente viável (IPEA, 2011, p. 8).

Isso leva a crer que o fato de uma parte dos intelectuais seguir desqualificando-na se deve ao conteúdo desestabilizador da ordem, no qual está em evidência um profundo desencontro de classes porque o objeto de disputa é o mais inalienável de todos os recursos, a base material da vida; que, por natureza, é irreprodutível. Daí seu caráter estratégico no que concerce a concepções de desenvolvimento e de sociedade, sendo oportuno nos posicionarmos já que a opção pela transformação é, antes de mais nada, construção que supõe a disposição em renunciar às "coisas pequenas", nas palavras de um camponês do sul do Brasil, ao mencionar mercadorias supérfluas que cada vez mais parecem conferir sentido às nossas vidas. Isso também pode soar romântico, mas não é. 


\section{Bibliografia}

ALTIERI, M. A.; TOLEDO, V. M. (2011) The agroecological revolution in Latin America: rescuing nature, ensuring food sovereignty and empowering peasants. The Journal of Peasant Studies, v. 38, n.3, p. 587612, julho.

ALMEIDA, R. A. (2006) (Re) criação do campesinato: identidade e distinção. São Paulo: UNESP.

BARTRA, A. (2008) El hombre de hierro: los limites socialies y naturales del capital. México: UNAM-ITACA.

BERNSTEIN, H. (2012) Dinámicas de clase y transformación agraria. México: Universidad Autónoma de Zacatecas.

CALABI, D.; INDOVINA, F. (1973) Sobre o uso capitalista do território. Archivio di studi urbani e regionali. Veneza, anno IV, n. 2, junho.

CHESNAIS, F. (2012) As raízes da crise econômica mundial. $O$ olho da História, n. 18, jul. 2012. Disponível em: <http://oolhodahistoria.org/n18/artigos/chesnais.pdf.>. Acessado em: 14 ago. 2012.

DESMARAIS, A. A. (2007) La Vía Campesina: globalization and the power of peasants. London: Pluto Press.

FAO/EBRD. (2012) Private sector for food security. Food an Agricultural Organization of the United Nations; European Bank for Reconstruction and Development. East Agri annual meeting. Istambul, sep. 2012. Disponível em: <http://www.eastagri.org/meetings/foodsecurity2012>. Acessado em: 16 set. 2012.

FERREYRA, M. A. (2012) A mudança nos valores relativos de preços na cadeia de valor do vinho argentino. Revista AGB TL, ano 9, n. 16, p. 10-42. HARVEY, D. (1996) Condição pós-moderna. São Paulo: Loyola.

IBGE. (2009) Instituto Brasileiro de Geografia e Estatística. Censo da Agricultura Familiar 2006. Rio de Janeiro: IBGE

IPEA. (2011) Código Florestal: implicações do PL 1876/99 nas áreas de reserva legal. Comunicados do IPEÁ. Instituto de Planejamento e Pesquisas Aplicadas, n. 96, junho.

MARX, K. (1974) O capital: Livro 3, volume 6. Rio de Janeiro: Civilização Brasileira. 
MAZOYER, M.; ROUDART, L. (2010) História das agriculturas no mundo: do neolítico à crise contemporânea. São Paulo: UNESP.

NAVARRO, Z. (2010) A agricultura familiar no Brasil: entre a política e as transformações da vida econômica. In: GASQUES, J. G.; VIEIRA FILHO, J. E. R.; NAVARRO, Z. (Orgs.) A agricultura brasileira: desempenho, desafios e perspectivas. Brasília: Ipea, p. 185-209.

OTERO, G. (2004) Adiós al campesinado? democracia y formación política de las clases en México rural. México: Universidad Autónoma de Zacatecas.

PARPART, J.; Veltmeyer, H. (2011) Estudios Críticos del desarrollo: la evolución de una idea. In: VELTMEYER, H. (Org.). Herramientas para el cambio: manual para los estudios críticos del desarrollo. Bolívia: Plural, p. 20-32.

PAULINO, E. T; FERREIRA, J. M.; MOREIRA, R.M.P. (2012) Relação custo-benefício na estratégia camponesa de produção de sementes próprias. Revista da ANPEGE, v. 8, n. 9, p. 61-72, janeiro-julho.

PETRAS, J.; VELTMEYER, H. (2003) Los campesinos y el estado en América: un pasado turbulento, un futuro incierto. Problemas del Desarrollo, v. 34, n. 131, p. 7-64.

PLOEG, J. D. V. D. (2008) Camponeses e impérios alimentares: lutas por autonomia e sustentabilidade na era da globalização. Porto Alegre: UFRGS.

PORTES, A.; HOFFMAN, K. (2003) Las estructuras de clase en América Latina: composición y cambios durante la época neoliberal. Caderno CEPAL, Série Políticas Sociales, ONU, n. 68, p. 1-51.

PORTO GONÇALVES, C.W. (2006) A globalização da natureza e a natureza da globalização. Rio de Janeiro: Civilização Brasileira.

PRADO JÚNIOR, C. (1981) A questão agrária no Brasil. 3. ed. São Paulo: Brasiliense.

RAFFESTIN, C. (1993) Por uma geografia do poder. São Paulo: Ática.

ROSSET, P. (2006) Alternativas à política fundiária de mercado: reforma agrária e soberania alimentar. In: SAUER, S.; PEREIRA, J. M. (Orgs). Capturando a terra: Banco Mundial, políticas fundiárias neoliberais e reforma agrária de mercado. São Paulo: Expressão Popular, p- 315-342. 
SHANIN, T. (1980) A definição de camponês: conceituação e desconceituação-o velho e o novo em uma discussão marxista. Estudos Cebrap, Petrópolis, n.26, p. 43-79.

SHANIN, T. (2008) Questões camponesas. In: PAULINO, E. T.; FABRINI, J. E. Campesinato e territórios em disputa. São Paulo: Expressão Popular, p. 139-160.

SANTOS, B. S. (2002) A crítica da razão indolente: contra o desperdício da experiência. São Paulo: Cortez.

VELTMEYER, H. (2011) Un sinopsis de la idea de desarrollo. Migración y Desarrollo, n. 14, p. 9-34.

WOLF, E. R. (1984) Guerras Camponesas do Século XX. São Paulo: Global.

Data de submissão: 03/10/2014.

Data de aceite: 12/02/2015. 